Anaesthesist $2021 \cdot 70$ (Suppl 1):S19-S29 https://doi.org/10.1007/s00101-020-00879-3 Published online: 27 November 2020 (c) Springer Medizin Verlag $\mathrm{GmbH}$, ein Teil von Springer Nature 2020

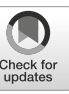

S. Kluge ${ }^{1,2,3,10,11} \cdot$ U. Janssens $s^{1,2,10} \cdot$ T. Welte ${ }^{1,3,10} \cdot$ S. Weber-Carstens ${ }^{2,4,10} \cdot$ G. Schälte ${ }^{4} \cdot$ B. Salzberger ${ }^{5} \cdot$ P. Gastmeier ${ }^{6} \cdot$ F. Langer G $^{7}$ M. Welper W. Mesthoff $^{4} \cdot$ M. Pfeifer ${ }^{3}$. F. Hoffmann ${ }^{2,8} \cdot$ B. W. Böttiger ${ }^{2,9} \cdot$ G. Marx ${ }^{2,4,10} \cdot$ C. Karagiannidis $\mathbf{s}^{1,2,3,10}$

' Deutsche Gesellschaft für Internistische Intensivmedizin und Notfallmedizin (DGIIN), Berlin, Germany

${ }^{2}$ Deutsche Interdisziplinäre Vereinigung für Intensiv- und Notfallmedizin (DIVI), Berlin, Germany

${ }^{3}$ Deutsche Gesellschaft für Pneumologie und Beatmungsmedizin (DGP), Berlin, Germany

${ }^{4}$ Deutsche Gesellschaft für Anästhesiologie und Intensivmedizin (DGAl), Nürnberg, Germany

${ }^{5}$ Deutsche Gesellschaft für Infektiologie (DGI), Munich, Germany

${ }^{6}$ Deutsche Gesellschaft für Hygiene und Mikrobiologie (DGHM), Münster, Germany

${ }^{7}$ Gesellschaft für Thrombose und Hämostaseforschung (GTH), Cologne, Germany

${ }^{8}$ Deutsche Gesellschaft für Kinder- und Jugendmedizin (DGKJ), Berlin, Germany

${ }^{9}$ Deutscher Rat für Wiederbelebung (German Resuscitation Council, GRC), Ulm, Germany

${ }^{10}$ ARDS Netzwerk Deutschland, Berlin, Germany

"Klinik für Intensivmedizin, Universitätsklinikum Hamburg-Eppendorf, Hamburg, Germany

\title{
Recommendations for treatment of critically ill patients with COVID-19
}

\section{Version 3 S1 guideline}

\section{Preamble} This is the English version of the article Kluge, $\mathrm{S}$,
Janssens, U., Welte, T. et al. Empfehlungen zur intensivmedizinischen Therapie von Patienten mit COVID-19 - 3. Version. Anaesthesist 69, 653-664 (2020). https://doi.org/10.1007/ 500101-020-00833-3. It is partly based on the article Kluge $S$, Janssens $U$, Welte $T$ et al. Recommendations for the intensive medical therapy of patients with COVID-19 MedKlinIntensivmed-Notfmed 115, 175-177 (2020). https://doi.org/10.1007/s00063-02000674-3.

These recommendations were developed in cooperation with the following societies: primary responsibility Deutsche Gesellschaft für Internistische Intensivmedizin und Notfallmedizin (DGIIN), Berlin, Deutsche Interdisziplinäre Vereinigung für Intensiv- und Notfallmedizin (DIVI), Berlin. In cooperation with Deutsche Gesellschaft für Pneumologie und Beatmungsmedizin (DGP), Berlin, Deutsche Gesellschaft für Anästhesiologie und Intensivmedizin (DGAI), Nürnberg, Deutsche Gesellschaft für Infektiologie (DGl), München, Deutsche Gesellschaft für Hygiene und Mikrobiologie (DGHM), Münster, Gesellschaft für Thrombose und Hämostaseforschung (GTH), Köln, Deutsche Gesellschaft für Kinder- und Jugendmedizin (DGKJ), Berlin, Deutscher Rat für Wiederbelebung (German Resuscitation Council, GRC), Ulm, ARDS Netzwerk Deutschland, Berlin.

Last amended 21 July 2020 (version 3).
This is the second update of the guidelines from 21 July 2020 (version 3). The first version was published in the journal Medizinische Klinik - Intensivmedizin und Notfallmedizin [1, 2].

Information on the recently published RECOVERY study on dexamethasone and on the official approval of remdesivir for COVID-19 as well as details regarding breathing system filters (Heat and Moisture Exchanger [HME] versus High-efficiency particulate air [HEPA]) and aspects of care for pediatric patients were added.

These recommendations aim to give guidance to physicians treating COVID19 patients on intensive care units (ICU). We acknowledge that the pandemic is in a dynamic stage and that experience and scientific evidence will grow. Comprehensive information on the pathogen and the trajectory of the pandemic is available online through the Robert Koch Institute (RKI, www.rki.de). We strongly recommend a multidisciplinary approach in the management and treatment of COVID-
19 patients. Aside from intensive care physicians and nurses, infectious disease and infection control specialists need to be part of the team.

\section{Introduction}

The first cases of the novel coronavirus (severe acute respiratory syndrome coronavirus 2, SARS-CoV-2) were noted in China in December 2019. Since then SARS-CoV-2 has been rapidly transmitted around the world resulting in a pandemic. The clinical picture of the infection is called coronavirus disease 2019 (COVID-19). Transmission of SARS$\mathrm{CoV}-2$ usually occurs via droplet infection during close contact. Therefore, a strict implementation of basic infection control measures, such as hand hygiene and the use of personal protection equipment (PPE) are essential. 


\section{Diagnostic approach}

\subsection{Specimens and testing}

The detection of SARS-CoV-2 is carried out from a nasopharyngeal or oropharyngeal swab using real-time reverse transcriptase polymerase chain reaction (RT-PCR). A patient with a negative test should be retested if there is a high clinical suspicion that they have contracted the virus. The swab might be negative while there is still infectious viral shedding in the lower airways at a later stage of the disease (pneumonia, ARDS). A PCR of endotracheal aspirates might be helpful in these cases.

At this point in time antibody testing primarily serves an epidemiological purpose. In our current understanding, detection of SARS-CoV-2 specific antibodies in serum indicates an exposure to SARS-CoV-2 but does not yet enable certain determination of the level of infectiousness or immunity [1].

\subsection{Clinical features}

In Germany the median age of patients with COVID-19 is 49 years [2] and of those admitted to the ICU it is 63 years [3]. Women and men are generally affected at a similar rate, $52 \%$ versus $48 \%$, respectively; however, men suffer twice as often from severe COVID-19 disease than women, and the mortality is higher [2]. Patients in need of in-hospital treatment usually have significant pre-existing medical conditions, most often regarding the cardiovascular system, e.g. hypertension, diabetes mellitus, chronic lung disease and obesity [4-6].

Frequently, COVID-19 presents as an airway infection with fever and dry cough as the key features. The only quasi pathognomonic symptom of COVID19 is anosmia, which occurs in $10-20 \%$ of the patients. In $81 \%$ of the patients the disease takes a mild course, $14 \%$ of the patients become severely ill and approximately $5 \%$ of the patients become critically ill [7]. Severe dyspnea with an increased labor of breathing (respiratory rate $>30 / \mathrm{min}$ ) and hypoxemic respiratory failure typically lead to admission to the ICU. At this stage bilateral pul- monary infiltrates can often be seen on imaging [8].

Admission to the ICU should be considered in COVID-19 patients presenting with the following clinical features:

- hypoxemia $\mathrm{SpO}_{2}<90 \%$ on $2-4 \mathrm{~L} / \mathrm{min}$ oxygen (without previous oxygen therapy) plus dyspnea

- respiratory rate $>25-30 / \mathrm{min}$

- systolic blood pressure $\leq 100 \mathrm{~mm} \mathrm{Hg}$

- elevated serum lactate

Severely affected patients may develop ARDS or, although not as often, bacterial superinfections and septic shock. Many critically ill patients on the ICU need to be treated with invasive ventilation $[3,9]$. Further complications seen in COVID-19 patients are arrythmia, myocardial dysfunction and pulmonary embolism as well as acute kidney failure and multiorgan dysfunction. On average, it takes approximately 10 days from showing first symptoms to ICU admission [10]. Median ICU length of stay is 9 days [3] and in ventilated patients 18 days [5].

\subsection{Laboratory changes}

In $80 \%$ of COVID-19 patients there is apparent lymphocytopenia and in one third of those patients this is accompanied by leukopenia. Most of the patients have elevated CRP but normal levels of procalcitonin; however, a bacterial superinfection might trigger a significant increase in procalcitonin [11]. Thrombocytopenia and an elevation of D-dimers and $\mathrm{LDH}$ are found in approximately $40 \%$ of the patients. Based on current knowledge, increased D-dimers, persistent lymphocytopenia and elevated LDH indicate a severe course of the disease and a limited prognosis [5]. A small proportion of patients also present with elevated troponin, the clinical implications of which are as yet unknown.

\subsection{Imaging}

Conventional chest radiographs show bilateral infiltrates in COVID-19 patients treated on the ICU. Even in early stages of the disease computed tomography (CT) can reliably detect typical bilateral subpleural ground-glass opacities and con- solidations in the lungs, whereas pleural effusions and lymphadenopathies are rare [12, 13]; however, CT findings are not specific for COVID-19 and can be found in other forms of viral pneumonia as well.

Due to the potential risks for healthcare workers and patients, we advise to only perform CT imaging in ICU patients when absolutely necessary for clinical decision making, e.g. in suspected pulmonary embolism [14]. Bedside imaging, e.g. ultrasonography, should be preferred otherwise, especially to assess the course of the disease during ICU admission.

\section{Infection control}

Patients should preferably be treated in isolation rooms, ideally with a functional anteroom for donning and doffing PPE. As the epidemic/pandemic progresses, isolation of patients in cohorts is reasonable.

Strict spatial separation of patients positive for SARS-CoV-2 should be carried out on the ward level. If possible, patients should be allocated to three different areas with distinct separation in terms of space and personnel:

- COVID-19 area (all patients positive for SARS-CoV-2)

- area for suspected cases

- non-COVID-19 area (all patients negative for SARS-CoV-2 and asymptomatic)

Room ventilation systems and air conditioning with active venting should not be turned off. If necessary frequent aeration by window ventilation, which reduces aerosol transmission, can be undertaken. Aeration between two rooms should be avoided.

Patients with COVID-19 should only be seen and cared for by trained personnel who do not have contact to other non-COVID-19 patients. The number of people working or visiting at the bedside should be kept to a minimum and be tailored to the actual patient needs, this also includes implementation of restrictions to visits by family and friends.

Personnel working at the bedside must strictly adhere to basic infection control 
measures, such as hand hygiene and consistently follow instructions on the use of PPE. According to the RKI, correct PPE consists of an impervious gown, gloves, tight fitting facemask (FFP2 or FFP3 in cases of strong exposure to aerosols due to certain procedures, e.g. intubation, bronchoscopy) as well as goggles. It is important to frequently train healthcare workers on structured donning and removing of PPE, especially on tight mask fitting and subsequent hand disinfection.

Comprehensive recommendations on infection control (rooms, protection of personnel, disinfection, cleaning, waste handling, patient transport and visitor regulations) can be found online on the website of the RKI [15]. Local guidelines and standard procedures for hospitals should be implemented by a multidisciplinary expert panel according to the local situation.

It seems reasonable to lift isolation requirements for ICU patients after COVID-19 based on the following scenarios:

1. Patient with endotracheal tube or tracheostomy

- first symptoms $>14$ days ago

- two sets of two negative SARSCoV-2 tests (nasopharyngeal or oropharyngeal swab plus endotracheal aspirate, simultaneously carried out)

2. Patient extubated or on noninvasive ventilation

- first symptoms $>14$ days ago

- two sets of two negative SARSCoV-2 tests (nasopharyngeal swab plus oropharyngeal swab, simultaneously carried out)

\section{Management of acute hypoxemic respiratory failure}

\subsection{Oxygen therapy, high-flow oxygen therapy, non-invasive ventilation}

First line options to support patients in respiratory failure and hypoxemia with oxygen are a simple nasal cannula, Venturi masks and high-flow nasal cannula (HFNC; - Fig. 1; [16]). As gas exchange worsens progressively and oxygen demand increases, CPAP therapy, non-in- vasive ventilation (NIV) or invasive ventilation need to be considered. The overarching goal is to ascertain adequate oxygenation. It is recommended to aim for $\mathrm{SpO}_{2} \geq 90 \%$ or $\mathrm{paO}_{2}>55 \mathrm{~mm} \mathrm{Hg}[17,18]$.

High-flow nasal cannula is often used in hypoxemic respiratory failure and reduces the need for intubation without affecting mortality [19]. Using NIV in moderate and severe ARDS fails in up to $50 \%$ of the patients, which is associated with a mortality as high as $50 \%$ in severe ARDS [20,21]. Not only the level of severity but also the extent of hypoxemic failure predicts NIV failure: a $\mathrm{PaO}_{2} / \mathrm{FiO}_{2} \leq 150 \mathrm{~mm} \mathrm{Hg}$ was shown to be a critical threshold for increased mortality [22]. Additionally, high tidal volumes ( $>9.5 \mathrm{ml} / \mathrm{kg}$ body weight, BW) during NIV within the first $4 \mathrm{~h}$ of treatment predict NIV failure [23]. Consequently, as those patients can deteriorate quickly, continuous monitoring and readiness for intubation is mandatory. Therefore, HFNC and NIV in acute respiratory failure should preferably be used in an ICU setting. In cases of progressive disease and clinical worsening despite all measures, intubation and invasive ventilation should be carried out in a timely manner and without delay if in the patient's interest and will.

\subsubsection{Aerosol formation}

Depending on the applied flow and pressure both HFCN and NIV are associated with increased aerosol formation, which in turn potentially increases the risk for virus transmission in COVID-19 patients $[24,25]$. As a principle, every breath leads to aerosol formation and the extent of it correlates with the depth of breathing [26]. Based on current knowledge, an increased amount of infectious aerosol particles is only detectable in patients on vented-NIV (versus non-vented NIV) and patients with a high load of secretions [27]. Studies on exhaled air and particle dispersion during HFNC and NIV were not able to show substantial exposure to exhaled air at more than $1 \mathrm{~m}$ distance to the face of the patient [28-30].

However, it is absolute necessary for everyone working with COVID-19 patients to use PPE correctly, especially ensuring a tight mask fit, while using HFNC
Anaesthesist 2021 · 70 (Suppl 1):S19-S29 https://doi.org/10.1007/s00101-020-00879-3 (c) Springer Medizin Verlag $\mathrm{GmbH}$, ein Teil von Springer Nature 2020

S. Kluge - U. Janssens - T. Welte · S. WeberCarstens · G. Schälte · B. Salzberger · P. Gastmeier - F. Langer - M. Welper . M. Westhoff $\cdot$ M. Pfeifer $\cdot$ F. Hoffmann B. W. Böttiger · G. Marx · C. Karagiannidis

\section{Recommendations for treatment of critically ill patients with COVID-19. Version 3 S1 guideline}

\section{Abstract}

Since December 2019 a novel coronavirus (severe acute respiratory syndrome coronavirus 2, SARS-CoV-2) has rapidly spread around the world resulting in an acute respiratory illness pandemic. The immense challenges for clinicians and hospitals as well as the strain on many healthcare systems has been unprecedented.

The majority of patients present with mild symptoms of coronavirus disease 2019 (COVID-19); however, 5-8\% become critically ill and require intensive care treatment. Acute hypoxemic respiratory failure with severe dyspnea and an increased respiratory rate $(>30 / \mathrm{min}$ ) usually leads to intensive care unit (ICU) admission. At this point bilateral pulmonary infiltrates are typically seen. Patients often develop a severe acute respiratory distress syndrome (ARDS).

So far, remdesivir and dexamethasone have shown clinical effectiveness in severe COVID-19 in hospitalized patients. The main goal of supportive treatment is to ascertain adequate oxygenation. Invasive mechanical ventilation and repeated prone positioning are key elements in treating severely hypoxemic COVID-19 patients. Strict adherence to basic infection control measures (including hand hygiene) and correct use of personal protection equipment (PPE) are essential in the care of patients. Procedures that lead to formation of aerosols should be carried out with utmost precaution and preparation.

and NIV [14]. The proper fit of the HFNC and the NIV mask on the patients' end is of course important to reduce aerosol formation in the first place [28]. During HFNC therapy patients wear an additional face mask on top of the cannula [31]. Studies using computer simulation models showed that this technique can 


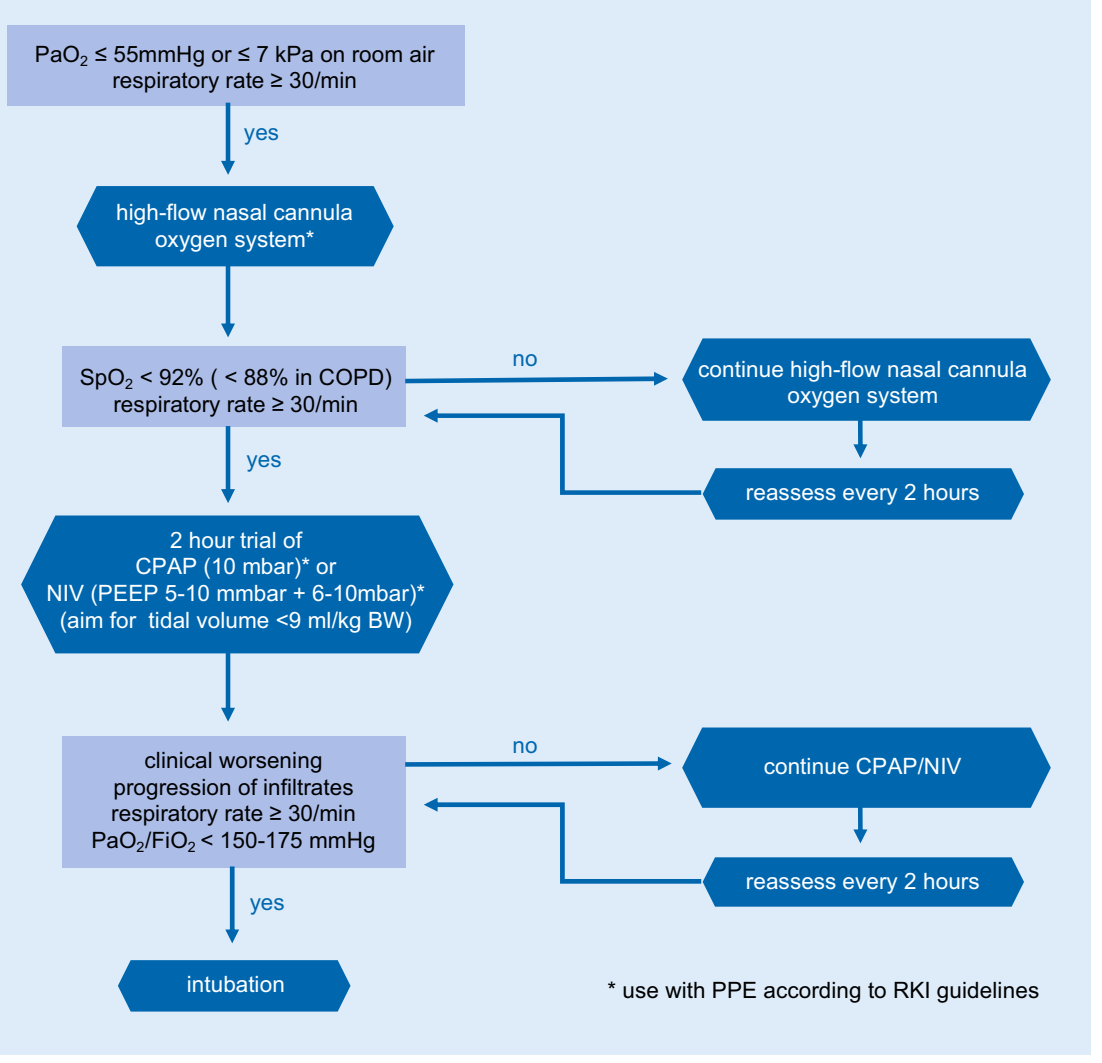

Fig. $1 \Delta$ Management and hierarchy of therapeutic options in acute respiratory failure associated with COVID-19. (adapted from [16]). NIV noninvasive ventilation, PEEP positive end-expiratory pressure, $C P A P$ continuous positive airway pressure, $C O P D$ chronic occlusive pulmonary disease, $B W$ body weight. $P P E$ personal protection equipment, RKI Robert Koch Institute

reduce particle dispersion during exhalation [32]. It is unclear though whether this has an impact on the performance of HFNC therapy. During NIV therapy air leakage needs to be kept at a minimum. Therefore, we recommend using non-vented oronasal face masks, full-face masks or helmets, especially in COVID19 patients. Respirators used in those patients should preferably be operated with dual limb tubing to reduce contamination of the environment. When using single limb tubing a viral filter needs to be placed between the interface and the exhaust system's whisper swivel or expiration valve [16]. This reduces aerosol dispersion, even in comparison with spontaneous breathing [27].

In conclusion, neither the use of HFNC or NIV in severe hypoxemia nor early intubation in less severely affected patients in order reduce exposure for personnel seem to be justified in patients with a SARS-CoV-2 infection. We recommend to only use HFNC or complemented by a protective visor [33, 34].

\subsection{Intubation}

Endotracheal intubation is considered a high-risk intervention in patients with suspected or confirmed SARS-CoV-2 infection [35]. Preparation and execution, especially with respect to hygiene precautions, need to follow specific protocols that were sufficiently communicated and practiced in advance $[36,37]$. Therefore, if possible, intubation should be performed electively and be well-planned; also, the number of people at the bedside should be kept to a minimum. The use of a transparent plastic sheet or a socalled intubation box to cover the patient during intubation has been debated with controversy but may be a reasonable option to reduce aerosol formation [38, 39].

If possible, intubation should be performed by the most experienced physician to minimize intubation attempts and time needed [40]. It is recommended to use video laryngoscopy for intubation to increase the distance between physician and patient during intubation given it is available and personnel are already trained in its use. We strongly encourage the use of a stylet for intubation, especially in video laryngoscopy it is imperative. Due to possible aerosol formation awake fibre-optic intubation should be avoided where possible. It may only be considered when options for other techniques are limited, e.g. a difficult airway. To minimize aerosol formation we suggest avoiding bag mask ventilation. Preoxygenation in the spontaneous breathing patient can be carried out with a tightfitting face mask using a bimanual technique and application of a positive endexpiratory pressure (PEEP) of $\leq 5 \mathrm{cmH}_{2} \mathrm{O}$. Intubation should be performed as a rapid sequence induction. After administration of the neuromuscular blocking agent and subsequent apnea, we suggest turning off the gas flow just before removing the mask in order to reduce aerosol dispersion. Immediately after intubation and before connection to the respirator, an HME filter should be placed on the tube. In general, it is recommended to 
Table 1 Interventions to minimize aerosol formation and exposure (adapted from [36])

\begin{tabular}{|c|c|}
\hline $\begin{array}{l}\text { Aerosol for- } \\
\text { mation by }\end{array}$ & Risk management \\
\hline \multirow{9}{*}{$\begin{array}{l}\text { Endotracheal } \\
\text { intubation }\end{array}$} & Avoid emergency intubation \\
\hline & Performed by the most experienced physician \\
\hline & Rapid sequence induction \\
\hline & Avoid bag mask ventilation \\
\hline & Optimal preparation and briefing \\
\hline & Consider video laryngoscopy to increase distance \\
\hline & Stylet for intubation \\
\hline & Consider transparent plastic sheet to cover patient's face \\
\hline & Consider intubation box \\
\hline \multirow[t]{5}{*}{ Preoxygenation } & Assure tight fitting mask \\
\hline & Using mask with both hands to hold in place \\
\hline & $\mathrm{FiO}_{2}$ of 1.0 \\
\hline & Maximum PEEP $5 \mathrm{cmH}_{2} \mathrm{O}$ \\
\hline & $\begin{array}{l}\text { Duration: } 3 \text { min of spontaneous breathing or } 1 \mathrm{~min} \text { of } 8-12 \text { deep breaths or } \\
1 \mathrm{~min} \text { CPAP/ASB of } 5 / 15 \mathrm{cmH}_{2} \mathrm{O}\end{array}$ \\
\hline \multirow{2}{*}{$\begin{array}{l}\text { Fibre-optic } \\
\text { intubation }\end{array}$} & Avoid where possible \\
\hline & Use local anesthetics \\
\hline Suction & Use closed systems \\
\hline \multirow{2}{*}{$\begin{array}{l}\text { Noninvasive } \\
\text { ventilation }\end{array}$} & Only when absolutely indicated \\
\hline & Assure tight fitting mask \\
\hline \multirow{2}{*}{$\begin{array}{l}\text { High-flow nasal } \\
\text { cannula }\end{array}$} & Only when absolutely indicated \\
\hline & Cover nose and mouth with mask \\
\hline Bronchoscopy & Only when absolutely indicated \\
\hline Tracheostomy & $\begin{array}{l}\text { Performed by the most experienced } \\
\text { Be aware of high level of aerosol formation in any technique } \\
\text { Consider postponing until patient is tested negative }\end{array}$ \\
\hline \multirow{3}{*}{$\begin{array}{l}\text { Disconnection } \\
\text { of tube }\end{array}$} & Leave HME filter on tube \\
\hline & Clamp tube \\
\hline & Respirator on stand-by during procedure \\
\hline \multirow[t]{6}{*}{ Extubation } & Avoid suction and inflation manoeuvres \\
\hline & Respirator on stand-by during procedure \\
\hline & Leave HME filter on tube \\
\hline & Consider transparent plastic sheet to cover patient's face \\
\hline & Postprocedural tight-fitting mask for oxygenation \\
\hline & Use regular protective face mask when adequate spontaneous breathing \\
\hline
\end{tabular}

only use high quality viral filters with an efficiency of $\geq 99.9 \%$, which are wellestablished and readily available on the market [41]. In theory, using mechanical HEPA filters may have advantages due to their lower permeability for smaller particles; however, to date there has been no specific research regarding the use of conventional filter systems in the context of COVID-19.
In the case of an anticipated or unanticipated difficult intubation, management needs to be adjusted according to the S1 guidelines on airway management [42]. If intubation is not feasible, a supraglottic airway device, e.g. laryngeal mask, should be established. In the event of a cannot intubate, cannot oxygenate (CICO) situation it is recommended to proceed directly to cricothyrotomy.

\subsection{Extubation}

Preferably, patients are extubated avoiding coughing or gagging and without any inflation maneuvers. Closed endotracheal suction just before extubation can be considered. We recommend leaving the HME filter on the tube for extubation and discard it together afterwards. Ideally, patients show sufficient oxygenation with oxygen face mask on low-flow oxygen [40, 41].

\subsection{Invasive ventilation and adjuvant treatment}

Due to the lack of randomized studies regarding ventilation strategies in COVID19 , current recommendations refer to the latest guidelines for invasive ventilation in acute respiratory failure $[17,43]$.

Especially in the early phase of COVID-19, lung mechanics are different from typical ARDS and show specific features. Lung compliance for instance is less impaired in the early stages and early on hypoxemia seems to be due to a pronounced ventilation perfusion mismatch rather than lack of recruitment $[44,45]$. This is further aggravated by vascular complications that significantly impair microcirculation [46].

For invasive ventilation in COVID-19 we recommend using closed inline suction catheters. In patients with ARDS it is generally recommended to use a tidal volume (TV) of $\leq 6 \mathrm{ml} / \mathrm{kg}$ ideal body weight and a plateau pressure of no more than $30 \mathrm{cmH}_{2} \mathrm{O}$. At this point in time there is no strict guidance on PEEP in COVID19 due to lack of robust data especially for the early stages of the disease. The PEEP therefore needs to be adjusted according to clinical findings and individual patient situation; however, from a pathophysiological standpoint it may be reasonable to avoid high PEEP in COVID-19 patients. If the patient develops a classical ARDS pattern, PEEP can be adjusted according to the ARDS network tables [43]. In severe ARDS with a $\mathrm{PaO}_{2} / \mathrm{FiO}_{2}$ $\leq 150 \mathrm{~mm} \mathrm{Hg}$, prone positioning should be administered consistently for $16 \mathrm{~h}$. If severe hypoxemia persists, prone positioning needs to be repeated. In individual cases, inhaled NO, the administra- 
tion of neuromuscular blocking agents and recruitment maneuvers may be considered as options for bridging to recovery. Where available, in patients with severe ARDS and refractory hypoxemia $\left(\mathrm{PaO}_{2} / \mathrm{FiO}_{2}<80\right.$ or $\left.60 \mathrm{~mm} \mathrm{Hg}\right)$ venovenous extracorporeal membrane oxygenation (vvECMO) may serve as a therapeutic option to ensure gas exchange. As it is a very complex and resource intensive treatment, all other measures should have been exhausted before considering ECMO and thorough evaluation of risks and benefits, including the presumed patient will, are warranted.

\subsection{Tracheostomy}

In the context of invasive ventilation tracheostomy may expedite weaning from the respirator and freeing up ICU capacities [47-49]. Furthermore, tracheostomy helps to minimize the use of sedative medication and facilitates weaning into spontaneous breathing, subsequently reducing the risk for critical-illness myopathy or polyneuropathy in long-term ventilated patients [50]; however, patients with improved organ function, specifically lung function, should be assessed for extubation and weaned from the ventilator when meeting the necessary requirements [51]. Yet, the risk for extubating failure is high in COVID-19 virus pneumonia and management for reintubation is associated with a higher risk of aerosol formation [35]. Despite recommendations for some specific circumstances, e.g. trauma patients, the decision for or against tracheostomy has to be made on an individual basis $[52,53]$. Regarding the time point, early tracheostomy in ventilated critically ill patients is not recommended by current guidelines [43]. It is important to keep in mind that viral load decreases over time in COVID-19; however, laryngeal damage and dysfunction, ventilator-associated atrophy of accessory muscles of respiration, and possible regaining of communication favors tracheostomy at an earlier time point [48]. For patients still experiencing multiorgan failure, however, tracheostomy may be considered at a later stage.

Patients need to be respiratory stable and able to sustain apneic episodes during the procedure before being considered for tracheostomy. Possible techniques are percutaneous dilatational tracheostomy, conventional surgical tracheostomy or a so-called modified hybrid tracheostomy. Percutaneous dilatational tracheostomy is a fast and uncomplicated bed-side approach in the ICU setting performed without surgical aids. The tight seal after placement of the cannula is another benefit of this technique. Reasons to follow a surgical approach on the other hand are the following: controlled surgical preparation of the trachea with reduced risk of contamination; safe airway even in the case of dislocation, for instance in prone positioning; possible avoidance of aerosol-forming bronchoscopy during the procedure and obesity, a common pre-existing condition in COVID-19 patients, as a relative contraindication for percutaneous dilatational tracheostomy.

As for intubation, the number of personnel at the bedside needs to be kept to a minimum during the procedure and the most experienced physician should perform the tracheostomy. Individual risk factors of the patient as well as local circumstances and expertise have to be considered when making decisions around tracheostomy and choosing a suitable technique.

\section{Cardiac arrest and cardiopulmonary resuscitation}

Studies from China showed respiratory failure as the major cause for cardiac arrest in COVID-19 patients, the initial rhythm often being asystole [54]. It is likely that aerosol formation and dispersion occurs during chest compression and airway management, which emphasises the need for proper use of PPE during cardiopulmonary resuscitation [55]. Defibrillation presumably does not cause aerosol formation. It is not recommended to check for audible breathing and lowering one's own face towards the patient's while determining cardiac arrest. If a defibrillator is readily available, it is suggested to check for shockable rhythms and then administer three sequential shocks when indicated. In the interim, additional personnel can put on their PPE; however, it is important to keep the number of personnel at the bedside to a minimum during resuscitation to reduce potential exposure [55]. Airway management should be carried out by the most experienced physician, where endotracheal intubation is preferred over other techniques. We recommend two-person bag mask ventilation, where one person manages the mask and the airway while the other one squeezes the bag to ventilate the chest in between chest compressions. It is suggested to perform chest compressions and ventilation in a 30:2 ratio when using supraglottic airway devices as well. Viral filters should be used in both manual and mechanical ventilation. In cases of prolonged cardiopulmonary resuscitation, a mechanical chest compression device may be considered [55]. Nonintubated patients should be turned over to a supine position if cardiac arrest occurs while the patient is in a prone position. In intubated patients, cardiopulmonary resuscitation may be feasible in the prone position. In this case chest compressions are to be applied in between the inferior borders of the shoulder blades [55]; however, the patient has to be turned if diastolic blood pressure remains below $25 \mathrm{~mm} \mathrm{Hg}$ or other issues occur in the prone position. Defibrillation pads can be placed anteroposterior or biaxillary when patients remain in the prone position during resuscitation. Since COVID-19 patients have a high incidence of deep vein thrombosis and pulmonary embolism, thrombolytic therapy should be considered where other causes of cardiac arrest are excluded [56].

\section{Prevention of venous thromboembolism}

Thromboembolic complications are common in COVID-19; they are usually of venous origin but can affect the arterial system as well $[57,58]$. Therefore, all hospitalized patients should receive primary venous thromboembolism prophylaxis with low molecular weight heparin (LMWH), dose-adjusted to high-risk groups. In cases of heparin intolerance or confirmed heparin-in- 
duced thrombocytopenia, fondaparinux serves as an alternative; however, observational studies suggest that, especially in critically ill patients, prophylactic doses of LMWH may be insufficient. Weighing up the individual risk of major bleeding and renal function, a more intensified anticoagulation regimen, e.g. with half-therapeutic intermediate doses of LMWH may be considered. We do not recommend routine use of therapeutic doses of anticoagulation without confirmed venous thromboembolism or outside of ECMO treatment; however, it can be reasonable in the individual case with a high level of suspicion, e.g. patients with high D-dimers plus/or acute worsening of gas exchange where timely imaging is not available. Because the development of pulmonary microthrombi is a specific feature of ARDS associated with COVID-19 [46], therapeutic anticoagulation can be considered for mechanically ventilated ICU patients on an individual basis as well [59]. In that case potential risks (e.g. pulmonary hemorrhage) need to be thoroughly weighed against the benefits. If renal function is severely impaired (cGFR $<30 \mathrm{ml} / \mathrm{min}$ ), anticoagulation with unfractionated heparin (UFH) is preferred. When aiming for therapeutic anticoagulation, anti-Xa activity for UFH may be used as a marker for effectiveness in case aPTT (activated partial thromboplastin time) does not adequately respond. Development of disseminated intravascular coagulation (DIC) with hyperfibrinolysis or consumptive coagulopathy is rare and occurs mostly in later stages of the disease. In order to reference COVID-19 related changes in hemostatic parameters appropriately and according to their specific pathophysiological basis, two new terms were recently introduced: COVID-19-associated coagulopathy (CAC) [60], and, pulmonary intravascular coagulopathy (PIC) [61]. It is reasonable to monitor relevant markers, e.g. platelets, prothrombin time/INR, fibrinogen, D-dimers and antithrombin, in patients with COVID-19 and complex coagulopathies.

\section{Therapy}

\subsection{Antibiotic therapy and general treatment principles}

As a principle, it is recommended to sample at least 2 blood cultures sets (aerobic and anaerobic at any one time) at the time of admission to ICU and whenever the patient's condition worsens [62]. In patients suspected of having a bacterial superinfection an empirical broad-spectrum antibiotic therapy should be started as soon as possible. A prophylactic antibiotic treatment merely on the basis of a SARS-CoV-2 infection is not recommended.

Fluid management should be handled restrictively, especially in cases with no signs of shock or tissue malperfusion, as fluid overload further impairs oxygenation.

\subsection{Specific pharmacologic therapy}

As our understanding constantly grows and new evidence may rapidly surface, the following recommendations for pharmacological interventions in COVID-19 should be tentatively interpreted and frequently reassessed.

There are two approaches concerning medicinal therapy for severely affected hospitalized COVID-19 patients: antiviral treatment and modulation of the immune response. In the following, we summarize data on pharmacologic therapies published in at least one case series or cohort study. In Europe, official approval for treatment in COVID-19 has so far only been granted for remdesivir.

\section{Antiviral therapies}

Chloroquine/hydroxychloroquine plus azithromycin. Potential benefits: in vitro proven efficacy, in vivo antiviral effectiveness is unclear. Impact on the clinical course has not been sufficiently investigated for hospitalized patients yet; there is only one nonpeer reviewed published study showing potential advantages of chloroquine in mild to moderate disease [63-66].

Potential risks: severe side effects of hydroxychloroquine are cardiac toxicity and retinal damage (high dose and prolonged treatment). Increased mortality for chloroquine diphosphate $(2 \times 600 \mathrm{mg} /$ day $)$ in critically ill patients. Side effects of azithromycin include drug interactions, prolonged QT syndrome, and arrhythmia.

Assessment: not recommended outside of clinical studies.

Interferon beta-1b. Potential benefits: in vitro antiviral activity against middle east respiratory syndrome(MERS)CoV. A randomized phase 2 trial showed improved antiviral effectiveness in combination with lopinavir and ritonavir compared to lopinavir and ritonavir alone. So far, no evidence on improved clinical outcomes [67].

Potential risks: can trigger influenzalike symptoms and hematopoietic dysfunction.

Assessment: not recommended outside of clinical studies.

Lopinavir/ritonavir. Potential benefits: modest in vitro antiviral activity. Randomized trial with small cohort size found no significant clinical advantage [68].

Potential risks: may cause severe drug interactions due to inhibition of CYP3A4. Contraindicated in severe liver failure. Potential side effects include nausea and diarrhea.

Assessment: not recommended outside of clinical studies.

Remdesivir. Potential benefits: in vitro good antiviral activity. No clinical advantage in mild to moderate COVID-19 cases but high-quality multinational, randomized, placebo-controlled trial showed clinical effectiveness for remdesivir in severe disease $[69,70]$.

Potential risks: hepatotoxicity. Possible side effects not yet fully understood and categorized.

Assessment: may be considered in severely affected hospitalized COVID-19 patients with pulmonary manifestations.

\section{Modulation of the immune response}

Steroids. Potential benefits: there has been controversy regarding steroids in ARDS. Especially in viral ARDS, e.g. 
SARS and influenza, steroids showed negative effects. Recently, results of the RECOVERY trial from the UK were published in the New England Journal of Medicine, where hospitalized patients were treated with either dexamethasone $(6 \mathrm{mg} /$ day once daily for 10 days) or standard therapy [71]. The primary endpoint was 28 -day mortality. In total, 2104 patients received dexamethasone treatment and 4321 standard therapy. Overall, 482 patients died during the study period: $22.9 \%$ of those treated with dexamethasone and $25.7 \%$ of those with standard therapy $(p<0.001)$. The effect was greatest in mechanically ventilated COVID-19 patients (29.3\% versus $41.4 \%$ mortality), even patients just on oxygen therapy \pm NIV without invasive ventilation benefited ( $23.2 \%$ versus $26.2 \%$ mortality) significantly. For patients less severely affected without oxygen therapy of any kind, dexamethasone did not have an advantage but rather showed negative effects.

Potential risks: immunosuppression, increased risk of bacterial superinfection.

Assessment: it is recommended to use dexamethasone $(6 \mathrm{mg}$ /day once daily for 10 days) in ventilated patients with COVID-19.

Tocilizumab. Potential benefits: competitive binding to soluble and cell surface IL-6-receptors leads to inhibition of IL-6 signal transduction pathways and attenuation of the inflammatory response. Cohort studies showed reduced rates of fever, a decrease in CRP and increase of lymphocyte count. Clinical effectiveness has not yet been shown $[72,73]$.

Potential risks: immunosuppression, increased risk of bacterial superinfection.

Assessment: not recommended outside of clinical studies.

Anakinra. Potential benefits: competitive binding to IL-1 receptor inhibits its signal transduction pathways. Effectiveness has been proven in case series of secondaryhemophagocyticlymphohistiocytosis and macrophage activation syndrome. A clinical benefit in COVID-19 has not yet been shown [74].

Potential risks: immunosuppression, increased risk of bacterial superinfection.
Assessment: not recommended outside of clinical studies.

\section{Others}

Convalescent plasma. Potential benefits: in theory there is analogue to convalescent plasma in other infectious diseases, e.g. Ebola, a possible advantage in clinical treatment of COVID-19; however, this has not yet been investigated in depth $[75,76]$.

Potential risks: hypersensitivity reaction (rare).

Assessment: not recommended outside of clinical studies.

\section{Summary}

So far, clinical effectiveness has only been shown for remdesivir and dexamethasone in hospitalized patients with severe COVID-19. In Europe, remdesivir was approved on 3 July 2020 for treatment of SARS-CoV-2 related pneumonia that requires oxygen therapy. Patients with hypoxemia and need for oxygen treatment benefit the most, there are no robust data available on ventilated patients yet. On the other hand, dexamethasone reduces mortality especially in mechanically ventilated COVID-19 patients.

At this time point, we do not recommend the use of any other pharmacological treatment option, neither antiviral nor immunomodulatory, outside of clinical trials and appropriate clinical settings. The University of Liverpool has published possible pharmacokinetic interactions of experimental COVID-19 therapies to aid decision making as well [77].

\section{Pediatric patients}

Generally, with a rate of only $1 \%$ of overall cases children and adolescent are far less affected by COVID-19 than adults $[9,78]$. Compared to adults children usually show a mild course of the disease and severe cases are rare. So far, the reason for this phenomenon remains unclear. Overall, pediatric patients rarely have to be admitted to a pediatric ICU (PICU) [79]. Severe cases of COVID-19 usually affect infants and toddlers as one third of patients with COVID-19 admitted to PICU were below 1 year of age. So far, only a few children have died from illness related to COVID-19 and mortality in the pediatric population is extremely low with $0.0018 \%$ [79]; however, it has to be acknowledged that current data are not robust enough to draw firm conclusions as asymptomatic COVID-19 cases may not have been appropriately counted. In Germany, so far 22 children with COVID-19 required admission to the PICU, and only 1 case of death has been reported (https://dgpi.de/covid-19survey-update-kw29/).

A systematic review on 2914 pediatric COVID-19 patients showed that $47 \%$ had fever at some point during the disease. Other frequent symptoms included coughing (48\%), pharyngitis (29\%) and gastrointestinal complaints (10\%), e.g. nausea and vomiting or diarrhea [79]. So far, only single cases of COVID-19 pneumonia and acute respiratory failure were reported $[80,81]$.

The same considerations and limitations apply for pediatric patients compared to adults when evaluating therapeutic options, such as oxygen insufflation, HFNC, noninvasive ventilation and intubation for risks of transmission for personnel and others. As in the adult population, so far there has not been a medicinal treatment with significant effectiveness in pediatric patients with COVID-19; as well, randomized controlled trials are lacking.

There have been several case reports referring to a COVID-19 associated acute hyperinflammatory syndrome in children that involves multiple organs (pediatric inflammatory multisystem syndrome, PIMS) [82-84]. Apart from fever, exanthema, conjunctivitis, polyserositis, gastrointestinal symptoms and edema, these patients often presented with vasoplegic shock. Some also showed symptoms similar to the Kawasaki syndrome, e.g. coronary involvement and left ventricular dysfunction [84]. In most of the cases, as with the classical Kawasaki syndrome, treatment was complemented with anti-inflammatory steroids (prednisone, prednisolone or methylprednisolone $2 \mathrm{mg} / \mathrm{kg} /$ day), high dose immunoglobulins $(2 \mathrm{~g} / \mathrm{kg})$ and, in some cases, acetylsalicylic acid $(50 \mathrm{mg} / \mathrm{kg})$ [85]. Biologicals like the TNF-alpha 
antagonist infliximab $(5 \mathrm{mg} / \mathrm{kg}$ i.v. over $2 \mathrm{~h}$, weekly) or the interleukin-1 receptor antagonist anakinra $(2-6 \mathrm{mg} / \mathrm{kg}$ BW/day subcutaneous) can be considered as rescue therapy if other options fail.

Symptoms of vasoplegic shock are treated with fluids and vasopressors. Hyperinflammatory syndromes are usually manageable within the first days of presentation; only a few cases treated with ECMO have been reported. Although a causal association of PIMS with COVID-19 is unclear, all cases in Germany are registered by the German Society of Pediatric Infectious Diseases (Deutsche Gesellschaft für Pädiatrische Infektiologie; https://dgpi. de/pims-survey-anleitung/) since May 2020.

\section{Ethical considerations}

In general, treatment of the critically ill COVID-19 patient follows the universal ethical principles of autonomy, welfare, do not harm, equity and human dignity. Two requirements are mandatory to justify and pursue medical treatment: 1) beginning and continuing treatment is medically indicated and 2) the treatment is in concordance with the patient's will. If the proposed treatment plan complies with both, it is obligatory to start or continue medical treatment. If one of the requirements is violated, it is not only permitted but rather demanded to change goals of care and limit treatment options [86].

Recommendations for the treatment of COVID-19 patients should also incorporate palliative care as one aspect of a comprehensive plan. In this respect, decision making against ICU treatment or a change in goals of care need to be respected and followed as well [87].

In the case of an uncontrollable upsurge in critically ill patients in Germany and a factual limitation of ICU resources despite all efforts to utilize maximum available ICU capacity, clinicians may use recently published recommendations for resource allocation in intensive care medicine in the context of the COVID19 pandemic to guide decision making [88].

\section{Management of ICU capacity}

The German ARDS-Netzwerk and the division Respiratory Failure within the German Interdisciplinary Association of Critical Care and Emergency Medicine (Deutsche Interdisziplinäre Vereinigung für Intensiv- und Notfallmedizin, DIVI) have launched a website in cooperation with the RKI, the DIVI intensive care medicine registry. It provides an overview of ICU bed capacities in Germany. All hospitals with critical care treatment options are required to fill in their occupied and available low-care, high-care and ECMO capacities. On 8 April 2020, a new federal regulation on maintenance and protection of ICU capacities in Germany took effect, making it mandatory for hospitals to report to the registry on a daily basis. The registry can be accessed at www.intensivregister. de.

\section{Corresponding address}

Prof. Dr. med. S. Kluge

Klinik für Intensivmedizin, Universitätsklinikum Hamburg-Eppendorf

Martinistr. 52, 20246 Hamburg, Germany

skluge@uke.de

\section{Compliance with ethical guidelines}

Conflict of interest. S. Kluge received research support from Ambu, ETView Ltd, Fisher \& Paykel, Pfizer and Xenios. He also received lecture fees from ArjoHuntleigh, Astellas, Astra, Basilea, C.R.Bard, Baxter, Biotest, CSL Behring, Cytosorbents, Fresenius, Gilead, MSD, Orion, Pfizer, Philips, Sedana, Sorin, Xenios and Zoll. He received consultant fees from AMOMED, Astellas, Baxter, Bayer, Fresenius, Gilead, MSD, Pfizer and Xenios. T. Welte received consultant fees from MSD, GSK, Boehringer, Immunogenic, Novartis, AstraZeneca and Roche. He received lecture fees and travel grants from Gilead and research support from Roche, MSD, Gilead, Immunogenic, Novartis, GSK and CSL Behring (DSMB). S. Weber-Carstens works in a research cooperation with Dräger. B. Salzberger received consultant fees from Falk Foundation, GSK, Roche and Sanofi, and, research support from Bosch-Stiftung, GSK and Biochryst. F. Langer received lecture and consultant fees as well as research support from Aspen, Bayer, Boehringer-Ingelheim, Bristol-Myers Squibb, Chugai, CSL Behring, Daiichi Sankyo, LEO Pharma, Pfizer, Roche, Sanofi, SOBI and Takeda. M. Westhoff received lecture fees from Actelion, Boehringer, Novartis and Löwenstein as well as research support by Bayer. M. Pfeifer received lecture fees from Astra-Zeneca, Boehringer, Chiesi, Glaxo-Smith-Kline, Novartis and Roche. He also received consultant fees from Boehringer, Chiesi, No- vartis and Roche, and travel support from Boehringer. B.W. Böttiger received lecture fees from Forum für medizinische Fortbildung (FomF), ZOLL and C.R. Bard. $G$. Marx received consultant fees and research support from Biotest, B.Braun und Adrenomed, he also received lecture compensation from $B$.Braun und Philips. C. Karagiannidis received consultant fees from Bayer und Xenios. U. Janssens, G. Schälte, P. Gastmeier, M. Welper and F. Hoffmann declare that they have no competing interests. For the process of assessment and evaluation of potential conflicts of interest please see AWMF-IMWi webpage and regulations.

For this article no studies with human participants or animals were performed by any of the authors. All studies performed were in accordance with the ethical standards indicated in each case.

The supplement containing this article is not sponsored by industry.

\section{References}

1. Robert Koch Institut (2020) Hinweise zur Testung von Patienten auf Infektion mit dem neuartigen Coronavirus SARS-CoV-2. https://www.rki.de/DE/ Content/InfAZ/N/Neuartiges Coronavirus/Vorl Testung_nCoV. Accessed 21 July 2020

2. Robert Koch Institut (2020) SARS-CoV-2 Steckbrief zur Coronavirus-Krankheit-2019 (COVID19). https://www.rki.de/DE/Content/InfAZ/ N/Neuartiges_Coronavirus/Steckbrief.html\# doc13776792bodyText15. Accessed 21 July 2020

3. Grasselli G, Zangrillo A, Zanella A, Antonelli M, Cabrini L, Castelli A et al (2020) Baseline characteristics and outcomes of 1591 patients infected with SARS-coV-2 admitted to ICus of the Lombardy region, Italy. JAMA 323(16):1574-1581

4. GuanWJ, Liang WH, Zhao Y, Liang HR, ChenZS, LiYM et al (2020) Comorbidity and its impact on 1590 patients with COVID-19 in China: a nationwide analysis. Eur Respir J55(5):2000547

5. Cummings MJ, Baldwin MR, Abrams D, Jacobson SD, Meyer BJ, Balough EM et al (2020) Epidemiology, clinical course, and outcomes of critically ill adults with COVID-19 in New YorkCity: a prospective cohort study. Lancet. https://doi.org/ 10.1016/S0140-6736(20)31189-2

6. Docherty AB, Harrison EM, Green CA, Hardwick HE, Pius R, Norman L et al (2020) Features of 20133 UK patients in hospital with covid-19 using the ISARIC WHO clinical characterisation protocol: prospective observational cohort study. BMJ 369:m1985

7. Wu Z, McGoogan JM (2020) Characteristics of and important lessons from the coronavirus disease 2019 (COVID-19) outbreak in China: summary of a report of 72314 cases from the Chinese center for disease control and prevention. JAMA 323(13):1239-1242. https://doi.org/10.1001/ jama.2020.2648

8. Chung M, Bernheim A, Mei X, Zhang N, Huang M, Zeng $X$ et al (2020) CT imaging features of 2019 novel coronavirus (2019-nCoV). Radiology 295(1):202-207. https://doi.org/10.1148/radiol. 2020200230

9. Richardson S, Hirsch JS, Narasimhan M, Crawford JM, McGinn T, Davidson KW et al (2020) Presenting characteristics, comorbidities, and outcomes among 5700 patients hospitalized with COVID-19 in the New York City area. JAMA 
323(20):2052-2059. https://doi.org/10.1001/ jama.2020.6775

10. Yang $X, Y u$ Y, Xu J, Shu H, Xia J, Liu H et al (2020) Clinical course and outcomes of critically ill patients with SARS-CoV-2 pneumonia in Wuhan, China: a single-centered, retrospective, observational study. Lancet Respir Med. https://doi.org/10. 1016/S2213-2600(20)30079-5

11. Guan WJ, Ni ZY, Hu Y, Liang WH, Ou CQ, He JX et al (2020) Clinical characteristics of coronavirus disease 2019 in China. N Engl J Med. https://doi. org/10.1056/NEJMoa2002032

12. Antoch G, Urbach $H$, Mentzel HJ, Reimer P, Weber W, Wujciak D (2020) SARS-CoV2/COVID-19. Empfehlungen für die Radiologische Versorgung - Eine Stellungnahme der Deutschen Röntgengesellschaft (DRG), der Deutschen Gesellschaft für Neuroradiologie (DGNR), der Gesellschaft für Pädiatrische Radiologie (GPR), der Deutschen Gesellschaft für Interventionelle Radiologie (DeGIR), des Berufsverbands der Neuroradiologen (BDNR) und des Berufsverbands der Radiologen (BDR). Rofo 192(5):418-421

13. Huang C, Wang Y, Li X, Ren L, Zhao J, Hu Y et al (2020) Clinical features of patients infected with 2019 novel coronavirus in Wuhan, China. Lancet. https://doi.org/10.1016/S0140-6736(20)30183-5

14. Liao X, Wang B, Kang Y (2020) Novel coronavirus infection during the 2019-2020 epidemic: preparing intensive care units-the experience in Sichuan Province, China. Intensive Care Med 46(2):357-360

15. Robert Koch Institut (2020) Empfehlungen des RobertKoch-Institutes zu Hygienemaßnahmen im Rahmen der Behandlung von Patienten mit einer Infektion durch SARS-CoV-2. https://www.rki.de/ DE/Content/InfAZ/N/Neuartiges_Coronavirus/ Hygiene.html. Accessed 21 July 2020

16. Pfeifer M, Ewig S, Voshaar T, Randerath W, Bauer T, Geiseler J et al (2020) Positionspapier zur praktischen Umsetzung der apparativen Differenzialtherapie der akuten respiratorischen Insuffizienz bei COVID-19. Deutsche Gesellschaft für Pneumologie und Beatmungsmedizin e.V. (DGP). Pneumologie. https://doi.org/10.1055/a1157-9976

17. Alhazzani W, Møller MH, Arabi YM, Loeb M, Gong MN, Fan E et al (2020) Surviving sepsis campaign: guidelines on the management of critically ill adults with coronavirus disease 2019 (COVID-19). Intensive Care Med 46(5):854-887

18. WHO (2020) Clinical management of COVID19. https://www.who.int/publications/i/item/ clinical-management-of-covid-19. Accessed 21 July 2020

19. Rochwerg B, Granton D, Wang DX, Helviz Y, Einav S, Frat JP et al (2019) High flow nasal cannula compared with conventional oxygen therapy for acute hypoxemic respiratory failure: a systematic review and meta-analysis. Intensive Care Med 45(5):563-572

20. Westhoff M, Schonhofer B, Neumann P, Bickenbach J, Barchfeld T, Becker H et al (2015) Nichtinvasive Beatmungals Therapie der akuten respiratorischen Insuffizienz. S3-Leitlinie herausgegeben von der Deutschen Gesellschaft für Pneumologie und Beatmungsmedizin e. V. Pneumologie 69(12):719-756

21. Rochwerg B, Brochard L, Elliott MW, Hess D, Hill NS, Nava S et al (2017) Official ERS/ATS clinical practice guidelines: noninvasive ventilation for acute respiratory failure. Eur Respir J. https://doi.org/10. 1183/13993003.02426-2016
22. Bellani G, Laffey JG, Pham T, Madotto F, Fan E, Brochard L et al (2017) Noninvasive ventilation of patients with acute respiratory distress syndrome. Insights from the LUNG SAFE study. Am J Respir Crit Care Med 195(1):67-77

23. Carteaux G, Millán-Guilarte T, De Prost N, Razazi K, Abid S, Thille AW et al (2016) Failure of noninvasive ventilation for de novo acute hypoxemic respiratory failure: role of tidal volume. Crit Care Med 44(2):282-290

24. Cabrini L, Landoni G, Zangrillo A (2020) Minimise nosocomial spread of 2019-nCoV when treating acute respiratory failure. Lancet 395(10225):685

25. Fowler RA, Guest CB, Lapinsky SE, Sibbald WJ, Louie M, Tang P et al (2004) Transmission of severe acute respiratory syndrome during intubation and mechanical ventilation. Am J Respir Crit Care Med 169(11):1198-1202

26. Schwarz K, Biller H, Windt $H$, Koch W, Hohlfeld JM (2015) Characterization of exhaled particles from the human lungs in airway obstruction. J Aerosol Med Pulm Drug Deliv 28(1):52-58

27. Simonds AK, Hanak A, Chatwin M, Morrell $M$, Hall A, Parker KH et al (2010) Evaluation of droplet dispersion during non-invasiveventilation, oxygen therapy, nebuliser treatment and chest physiotherapy in clinical practice: implications for management of pandemic influenza and other airborne infections. Health Technol Assess 14(46):131-172

28. Hui DS, Chow BK, Lo T, Tsang OTY, Ko FW, Ng SS et al (2019) Exhaled air dispersion during high-flow nasal cannula therapy versus CPAP via different masks. Eur Respir J53(4):1802339. https://doi.org/ 10.1183/13993003.02339-2018

29. Hui DS, Chow BK, Ng SS, Chu LCY, Hall SD, Gin T et al (2009) Exhaled air dispersion distances during noninvasive ventilation via different respironics face masks. Chest 136(4):998-1005

30. Hui DS, Hall SD, Chan MT, Chow BK, Tsou JY, Joynt GM et al (2006) Noninvasive positivepressure ventilation: an experimental mode to assess air and particle dispersion. Chest 130(3):730-740

31. Wachs C, Grensemann J, Kluge S (2020) High-FlowSauerstofftherapie - Schritt für Schritt. Dtsch Med Wochenschr 145(10):693-697

32. Leonard S, Atwood CW Jr., Walsh BK, DeBellis RJ, Dungan GC, Strasser W et al (2020) Preliminary findings on control of dispersion of aerosols and droplets during high-velocity nasal insufflation therapy using a simple surgical mask: implications for high-flow nasal cannula. Chest 158(3):1046-1049. https://doi.org/10.1016/j. chest.2020.03.043

33. Darwiche K, Ross B, Gesierich W, Petermann C, Huebner RH, Grah C et al (2020) Empfehlungen zur Durchführung einer Bronchoskopie in Zeiten der COVID-19-Pandemie. Pneumologie 74(5):260-262

34. Greenland JR, Michelow MD, Wang L, London MJ (2020) COVID-19 infection: implications for perioperative and critical care physicians. Anesthesiology 132(6):1346-1361

35. Cook TM, El-Boghdadly K, McGuire B, McNarry AF, Patel A, Higgs A (2020) Consensus guidelines for managing the airway in patients with COVID19:guidelines from the difficult airway society, the association of Anaesthetists the intensive care society, the faculty of intensive care medicine and the royal college of anaesthetists. Anaesthesia 75(6):785-799

36. Schälte GKF, Didion N, Pirlich N, Bickenbach J, Rehm M et al (2020) Besonderheiten des
Atemwegsmanagements bei Patienten mit vermuteter oder gesicherter COVID-19 Erkrankung und bei Patienten ohne Infektion während der Corona-Pandemie. Empfehlungen von DGAl und BDA. Anasth Intensivmed 61:132-136

37. Caputo KM, Byrick R, Chapman MG, Orser BJ, Orser BA (2006) Intubation of SARS patients: infection and perspectives of healthcare workers. Can J Anaesth 53(2):122-129

38. Dalli J, Khan MF, Marsh B, Nolan K, Cahill RA (2020) Evaluating intubation boxes for airway management. Br JAnaesth 125(3):e293-e295

39. Begley JL, Lavery KE, Nickson CP, Brewster DJ (2020) The aerosol box for intubation in COVID19 patients: an in-situ simulation crossover study. Anaesthesia 75(8):1014-1021. https://doi.org/10. 1111/anae.15115

40. Peng PWH, Ho PL, HotaSS (2020) Outbreak of a new coronavirus: what anaesthetists should know. $\mathrm{Br} J$ Anaesth 124(5):497-501

41. Orser BA (2020) Recommendations for endotracheal intubation of COVID-19 patients. Anesth Analg 130(5):1109-1110

42. Piepho T, Cavus E, Noppens R, Byhahn C, Dörges V, Zwissler B, Timmermann A (2015) S1 Leitlinie: Atemwegsmanagement

43. AWMF (2017) S3-Leitlinie Invasive Beatmung und Einsatz extrakorporaler Verfahren bei akuter respiratorischer Insuffizienz. https://www.awmf. org. Accessed 4 Dec 2017

44. Gattinoni L, Chiumello D, Caironi P, Busana M, RomittiF,BrazziLetal(2020)COVID-19pneumonia: different respiratory treatments for different phenotypes? Intensive Care Med 46(6):1099-1102. https://doi.org/10.1007/s00134-020-06033-2

45. Gattinoni L, Coppola S, Cressoni M, Busana M, RossiS, ChiumelloD(2020)COVID-19 does notlead to a "typical" acute respiratory distress syndrome. Am J Respir Crit Care Med 201(10):1299-1300

46. Ackermann M, Verleden SE, Kuehnel M, Haverich A, Welte T, Laenger F et al (2020) Pulmonary vascular endothelialitis, thrombosis, and angiogenesis in Covid-19. N Engl J Med 383(2):120-128. https:// doi.org/10.1056/NEJMoa2015432

47. AWMF (2019) S2k-Leitlinie Prolongiertes Weaning. https://www.awmf.org/leitlinien/detail/ll/020015.html. Accessed 21 July 2020

48. McGrath BA, Brenner MJ, Warrillow SJ, Pandian V, Arora A, Cameron TS et al (2020) Tracheostomy in the COVID-19 era: global and multidisciplinary guidance. Lancet Respir Med. https://doi.org/10. 1016/S2213-2600(20)30230-7

49. Hosokawa K, Nishimura M, Egi M, Vincent JL (2015) Timing of tracheotomy in ICU patients: a systematic review of randomized controlled trials. Crit Care 19:424

50. Griffiths RD, Hall JB (2010) Intensive care unitacquired weakness. Crit Care Med 38(3):779-787

51. Girard TD, Kress JP, Fuchs BD, Thomason JW, Schweickert WD, Pun BT et al (2008) Efficacy and safety of a paired sedation and ventilator weaning protocol for mechanically ventilated patients in intensive care (awakening and breathing controlled trial): a randomised controlled trial. Lancet 371(9607):126-134

52. Wang R, Pan C, Wang X, Xu F, Jiang S, Li M (2019) The impact of tracheotomy timing in critically ill patients undergoing mechanical ventilation: a meta-analysis of randomized controlled clinical trials with trial sequential analysis. Heart Lung 48(1):46-54

53. Elkbuli A, Narvel RI, Spano PJ 2nd, Polcz V, Casin A, Hai $S$ et al (2019) Early versus late tracheostomy: 
is there an outcome difference? Am Surg 85(4):370-375

54. Shao F, Xu S, Ma X, Xu Z, Lyu J, Ng M et al (2020) Inhospital cardiac arrest outcomes among patients with COVID-19 pneumonia in Wuhan, China. Resuscitation 151:18-23

55. Deutscher Rat für Wiederbelebung - German Resuscitation Council (GRC) e.V.(2020) Empfehlungen des International Liaison Committee on Resuscitation (ILCOR), des Europäischen Rates für Wiederbelebung (ERC) und des Deutschen Rates für Wiederbelebung/German Resuscitation Council (ERC) zur CPR bei Patienten mit COVID19. https://www.grc-org.de/ueber-uns/aktuelles. Accessed 21 July 2020

56. Böttiger BW, Wetsch WA (2019) Pulmonary embolism cardiac arrest: thrombolysis during cardiopulmonary resuscitation and improved survival. Chest 156(6):1035-1036

57. Wichmann $D$, Sperhake JP, Lütgehetmann $M$, Steurer S, Edler C, Heinemann A et al (2020) Autopsy findings and venous thromboembolism in patients with COVID-19. Ann Intern Med. https:// doi.org/10.7326/M20-2003

58. Langer F, Kluge S, Klamroth R, Oldenburg J (2020) Coagulopathy in COVID-19 and its implication for safe and efficacious thromboprophylaxis. Hamostaseologie 40(3):264-269. https://doi.org/ 10.1055/a-1178-3551

59. Paranjpe I, Fuster V, Lala A, Russak A, Glicksberg BS, Levin MA et al (2020) Association of treatment dose anticoagulation with in-hospital survival among hospitalized patients with COVID-19. J Am Coll Cardiol 76(1):122-124. https://doi.org/10.1016/j. jacc.2020.05.001

60. Connors JM, Levy JH (2020) COVID-19 and its implications for thrombosis and anticoagulation. Blood 135(23):2033-2040. https://doi.org/10. 1182/blood.2020006000

61. Fogarty H, Townsend L, Ni Cheallaigh C, Bergin C, Martin-Loeches I, Browne P et al (2020) COVID19 coagulopathy in Caucasian patients. Br J Haematol 189(6):1044-1049. https://doi.org/10.1111/bjh. 16749

62. Brunkhorst FM, Weigand MA, Pletz M, Gastmeier P, Lemmen SW, Meier-Hellmann A et al (2020) S3Leitlinie Sepsis - Prävention, Diagnose, Therapie und Nachsorge - Langfassung. Med Klin Intensivmed Notfmed 115(2):37-109

63. Borba MGS, Val FFA, Sampaio VS, Alexandre MAA, Melo GC, Brito M et al (2020) Effect of high vs low doses of chloroquine diphosphate as adjunctive therapy for patients hospitalized with severe acute respiratory syndrome coronavirus 2 (SARS-coV-2) infection: a randomized clinical trial. JAMA Netw Open 3(4):e208857

64. Wang M, Cao R, Zhang L, Yang X, Liu J, Xu M et al (2020) Remdesivir and chloroquine effectively inhibit the recently emerged novel coronavirus (2019-nCoV) in vitro. Cell Res 30(3):269-271

65. Geleris J, Sun Y, Platt J, Zucker J, Baldwin M Hripcsak G et al (2020) Observational study of hydroxychloroquine in hospitalized patients with Covid-19. NEngl J Med 382(25):2411-2418

66. Chen Z, Hu J, Zhang Z et al (2020) Efficacy of hydroxychloroquine in patients with COVID-19: results of a randomized clinical trial. medRxiV. https://doi.org/10.1101/2020.03.22.20040758

67. Hung IF, Lung KC, Tso EY, Liu R, Chung TW, Chu MYet al (2020) Triple combination of interferon beta-1b, lopinavir-ritonavir, and ribavirin in the treatment of patients admitted to hospital with COVID-19: an open-label, randomised, phase 2 trial. Lancet. https://doi.org/10.1016/S0140-6736(20)31042-4
68. Cao B, Wang Y, Wen D, Liu W, Wang J, Fan G et al (2020) A trial of lopinavir-ritonavir in adults hospitalized with severe Covid-19. N Engl J Med 382(19):1787-1799

69. Beigel JH, Tomashek KM, Dodd LE, Mehta AK, Zingman BS, Kalil AC et al (2020) Remdesivir for the treatment of Covid-19-preliminary report. NEngl JMed. https://doi.org/10.1056/NEJMoa2007764

70. Wang Y, Zhang D, Du G, Du R, Zhao J, Jin Y et al (2020) Remdesivir in adults with severe COVID-19. a randomised, double-blind, placebo-controlled, multicentre trial. Lancet 395(10236):1569-1578

71. Horby P, Lim WS, Emberson JR, Mafham M, Bell JL, Linsell L et al (2020) Dexamethasone in hospitalized patients with Covid-19_-preliminary report. N Engl J Med. https://doi.org/10.1056/ NEJMoa2021436

72. Colaneri M, Bogliolo L, Valsecchi $P$, Sacchi $P$, Zuccaro V, Brandolino F et al (2020) Tocilizumab for treatment of severe COVID-19 patients: preliminary results from SMAtteo COvid19REgistry (SMACORE). Microorganisms 8(5):695. https://doi. org/10.3390/microorganisms8050695

73. Luo P, Liu Y, Qiu L, LiuX, Liu D, Li J (2020) Tocilizumab treatment in COVID-19: a single center experience. J Med Virol. https://doi.org/10.1002/jmv.25801

74. Cavalli G, De Luca G, Campochiaro C et al (2020) Interleukin-1 blockade with high-dose anakinrain patients with COVID-19, acute respiratory distress syndrome, and hyperinflammation: a retrospective cohort study. Lancet Rheumatol. https://doi. org/10.1016/S2665-9913(20)30127-2

75. Valk SJ, Piechotta V, Chai KL, Doree C, Monsef I, Wood EM et al (2020) Convalescent plasma or hyperimmune immunoglobulin for people with COVID-19: a rapid review. Cochrane Database Syst Rev. https://doi.org/10.1002/14651858. CD013600

76. Li L, Zhang W, Hu Y, Tong X, Zheng S, Yang J et al (2020) Effect of convalescent plasmatherapy on time to clinical improvement in patients with severe and life-threatening COVID-19: a randomized clinical trial. JAMA. https://doi.org/10. 1001/jama.2020.10044

77. University of Liverpool (2020) COVID-19 drug interactions. http://www.covid19-druginteractions. org. Accessed 21 July 2020

78. Gudbjartsson DF, Helgason A, Jonsson H, Magnusson OT, Melsted P, Norddahl GL et al (2020) Spread of SARS-CoV-2 in the Icelandic population. NEngl J Med 382(24):2302-2315

79. Patel NA (2020) Pediatric COVID-19: systematic review of the literature. Am J Otolaryngol 41(5):102573

80. Dong $Y$, Mo X, Hu Y, Qi X, Jiang F, Jiang Z et al (2020) Epidemiology of COVID-19 among children in China. Pediatrics 145(6):e20200702. https://doi. org/10.1542/peds.2020-0702

81. Tagarro A, Epalza C, Santos M, Sanz-Santaeufemia FJ, Otheo E, Moraleda C et al (2020) Screening and severity of coronavirus disease 2019 (COVID-19) in children in Madrid, Spain. JAMA Pediatr. https://doi.org/10.1001/jamapediatrics. 2020.1346

82. Whittaker E, Bamford A, Kenny J, Kaforou M, Jones CE, Shah P et al (2020) Clinical characteristics of 58 children with a pediatric inflammatory multisystem syndrome temporally associated with SARS-coV-2. JAMA 324(3):259-269. https://doi. org/10.1001/jama.2020.10369

83. Riphagen S, Gomez X, Gonzalez-Martinez C, Wilkinson N, Theocharis P (2020) Hyperinflammatory shock in children during COVID-19 pandemic. Lancet 395(10237):1607-1608
84. Ramcharan $\mathrm{T}$, Nolan $\mathrm{O}$, Lai $\mathrm{CY}$, Prabhu N, Krishnamurthy R, Richter AG et al (2020) Paediatric inflammatory multisystem syndrome: temporally associated with SARS-coV-2 (PIMS-TS): cardiac features, management and short-term outcomes at aUK tertiary paediatric hospital. Pediatr Cardiol. https://doi.org/10.1007/s00246-020-02391-2

85. Verdoni L, Mazza A, Gervasoni A, Martelli L, Ruggeri M, Ciuffreda M et al (2020) An outbreak of severe Kawasaki-like disease at the Italian epicentre of the SARS-CoV-2 epidemic: an observational cohort study. Lancet 395(10239):1771-1778

86. Janssens U, Burchardi N, Duttge G, Erchinger R, Gretenkort P, Mohr M et al (2012) Therapiezieländerung und Therapiebegrenzung in der Intensivmedizin. Dtsch Interdiszip Ver Intensiv NotfMed 3:103-107

87. Deutsche Gesellschaft für Palliativmedizin (2020) Stellungnahmen 2020. https:// www.dgpalliativmedizin.de/category/178stellungnahmen-2020.html. Accessed 21 July 2020

88. Dutzmann J, Hartog $C$, Janssens $U$, Jöbges $S$, Knochel K, Marckmann M et al (2020) Entscheidungen über die Zuteilung intensivmedizinischer Ressourcen im Kontext der COVID-19-Pandemie. https://www.divi.de/register/aktuelleinformationen. Accessed 21 July 2020 